\title{
PENERAPAN KNOWLEDGE SHARING DALAM MENDORONG PRESTASI MAHASISWA MANAJEMEN BISNIS MARITIM DI POLITEKNIK PERKAPALAN NEGERI SURABAYA
}

\author{
Sintia Novilia Putri, Fitri Wahyuningtyas, Novia nur sa'adah, Nisma Mutiara D.S, \\ Denny Oktavina Radianto
}

Politeknik Perkapalan Negeri Surabaya.

Email: noviliasintia@gmail.com

\begin{abstract}
Abstrak
Knowledge Management adalah serangkaian proses mengelola, menciptakan, dan berbagi pengetahuan untuk mengoptimalkan pencapaian misi dan tujuan organisasi. Padatnya jam kuliah di dalam kampus akan berpengaruh terhadap mahasiswa dengan kurangnya pengetahuan dan pengalaman mereka akan pembelajaran di luar jam kuliah. Tujuan dari penelitian ini adalah untuk dapat memperbaiki sistem pembelajaran yang terdapat di Manajemen Bisnis Maritim Politeknik Perkapalan Negeri Surabaya. Metode yang penulis gunakan dalam penelitian ini adalah wawancara dan kuisioner. Teori yang penulis gunakan dalam penelitian ini adalah mode SECI dengan cara "Tacit to Tacit (Socialization)" yaitu penulis melakukan wawancara dengan mahasiswa, setelah itu hasil dari wawancara tersebut akan disampaikan ke direksi. Hasil dari penelitian ini menunjukkan bahwa dengan adanya penerapan sharing knowledge manfaat yang didapatkan mahasiswa sangatlah banyak, selain peningkatan prestasi dalam bidang akademik dan non akademik, para mahasiswa juga dapat sekaligus meningkatkan soft skill mereka dalam kegiatan bermasyarakat.
\end{abstract}

\begin{abstract}
Knowledge Management is a series of processes to manage, create and share knowledge to optimize the achievement of the mission and goal of the organization. Tight at college on campus will have an effect on students with the lack of knowledge and experience they will be learning outside at college. The purpose of this research is to be able to improve the learning system that is available in Management Business Maritime Polytechnic Shipping of Surabaya. The method that writers use in this study is the interview and the questionnaire. The theory that writers use in this study is the vogue SECI in a way "Tacit to Tacit (Socialization)" the author conducted interviews with students, after it be the result of the interview would be presented to the board of directors. As a result of this study shows that with the implementation of the sharing of knowledge of the benefits of the students are many, in addition to an increase in achievement in the field of academic as well as academic, the students also can as well as improve soft skills they in the activities of society.
\end{abstract}

Keywords: Knowledge Management, Tacit to Tacit, Sharing Knowledge, Capturing Knowledge, Capturing Knowledge. 


\section{Pendahuluan}

Menurut Peraturan Pemerintah Republik Indonesia Nomor 61 Tahun 1999, perguruan tinggi merupakan satuan pendidikan tinggi yang menyelenggarakan pendidikan tinggi yang bertujuan menyiapkan peserta didik menjadi anggota masyarakat yang memiliki kemampuan akademik profesional yang dapat menerapkan, mengembangkan, dan memperkaya khasanah ilmu pengetahuan, teknologi serta menyebarkan dan mengupayakan penggunaanya untuk meningkatkan taraf kehidupan masyarakat dan memperkaya kebudayaan nasional.

Dalam upaya ini, maka selaku dari pihak perguruan tinggi perlu untuk menerapkan Knowledge Management untuk meningkatkan performa mereka. Knowledge Management adalah serangkaian proses mengelola, menciptakan, dan berbagi pengetahuan untuk mengoptimalkan pencapaian misi dan tujuan organisasi. Sebagai suatu strategi, knowledge management sangat memberikan banyak manfaat bagi peningkatan kinerja organisasi. Penerapan knowledge management yang sistematis akan amat membantu organisasi dalam mencapai tujuan organisasi.

Dalam upaya pengembangan ini, dapat dilakukan beberapa hal yang bisa diterapkan didalam lingkungan perguruan tinggi. Sharing knowledge, capturing knowledge, sangat penting untuk kesuksesan praktik manajemen pengetahuan di semua organisasi termasuk universitas. Jika diterapkan dengan benar, hal ini akan memberikan manfaat yang penting bagi prestasi mahasiswa maupun bagi perguruan tinggi itu sendiri.

Menyadari hal itu, maka pada studi ini dibahas bagaimana pentingnya penerapan manajemen pengetahuan (Knowledge management) baik secara organisasi maupun secara personal (individu). Selain itu, akan dijelaskan pula metode penelitian dan teori yang digunakan dalam paper ini. Diharapkan, pengetahuan yang akan dijalankan terdapat arahan atau aturan yang mendukung dalam menerapkannya.

Pada bagian selanjutnya dijelaskan tentang hasil dari penelitian paper ini sesuai dengan teori-teori yang sudah ada sebagai acuan atau arahan. Kesimpulan dan daftar pustaka disajikan pada bagian keenam dan ketujuh secara berurutan.

Adapun tujuan dari penelitian ini adalah untuk mengetahui penerapan Knowledge Sharing di lingkungan mahasiswa Manajemen Bisnis Maritim PPNS, Untuk mengetahui proses SECI di lingkungan mahasiswa Manajemen Bisnis Maritim PPNS, dan Untuk mengetahui manfaat yang didapat setelah menerapkan Knowledge Sharing di lingkungan mahasiswa Manajemen Bisnis Maritim PPNS.

\section{Kajian Pustaka}

Definisi Knowledge Management menurut Nonaka \& Takeuchi (1994) adalah alat manajemen yang membenarkan keyakinan bahwa pengetahuan menjadi aset untuk meningkatkan kapasitas organisasi agar mampu bekerja lebih efektif. Menurut Delphi (1998), Knowledge Management adalah praktik dan teknologi untuk memfasilitasi proses penciptaan dan pembagian pengetahuan. Menurut Newman dan Conrad (1999), Knowledge Management adalah suatu disiplin yang mencari peningkatan kinerja individual dan organisasi dengan mengelola dan mengungkit nilai saat ini dan nilai yang akan dating dari aset pengetahuan. Menurut Jann dan Lantu (2006), Knowledge Management adalah proses sistematik untuk menemukan, memilih, mengorganisasikan, menyarikan dan menyajikan pengetahuan dengan cara tertentu, sehingga para anggota organisasi mampu memanfaatkan dan meningkatkan penguasaan pengetahuan dalam suatu bidang kajian yang spesifik, untuk kemudian ada proses institusionalisasi agar pengetahuan yang diciptakan menjadi pengetahuan organisasi.

Jadi dapat disimpulkan bahwa, Knowledge Management adalah aktivitas manajemen dan proses untuk mengungkit tumbuh kembangnya pengetahuan dalam organisasi dengan mengelola pengetahuan untuk meningkatkan daya kompetisi perusahaan melalui perbaikan proses 
penciptaan dan penggunaan pengetahuan individual maupun organisasional.

Perpindahan pengetahuan (knowledge transfer) di dalam organisasi melalui gabungan kedua pengetahuan tersebut. Nonaka dan Takeuchi (1995) menawarkan empat model pembentukan dan perpindahan pengetahuan. Model ini sering disebut sebagai model SECI.

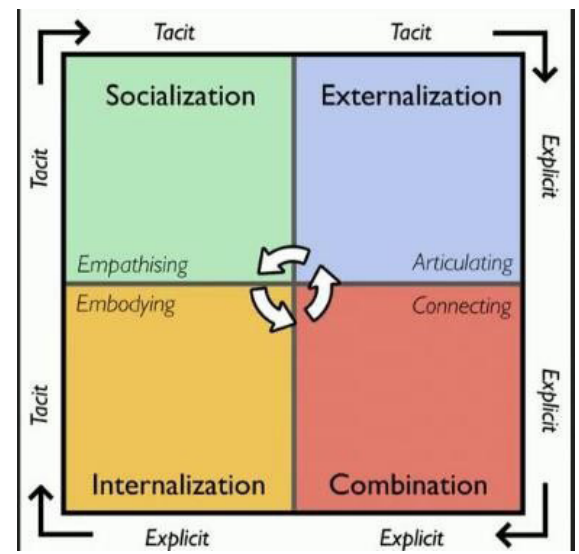

Gambar 1. Pola dasar KM-creation (sumber:https:// customerthink.com)

a. Tacit to tacit communication (Sosialisasi) merupakan adalah proses berbagi pengetahuan dan membuat pengetahuan tacit sebagi model mental dan keterampilan teknis. Pengetahuan tacit bisa diperoleh melalui observasi, imitasi, dan praktek. Muncul karena adanya aktivitas berbagi dan menciptakan pengetahuan tacit melalui pengalaman langsung.

b. Tacit to explicit communication (Eksternalisasi) merupakan proses artikulasi tacit knowledge dalam bentuk konsep eksplisit dalam bentuk metafora, analogis, hipotesis, atau model (mis., Brainstorming).

c. Explicit to explicit communication (kombinasi) merupakan proses konsep sistemis ke dalam sistem pengetahuan dengan menggabungkan pengetahuan eksplisit yang berbeda. Pengetahuan eksplisit dipindah melalui media seperti dokumen, pertemuan, email atau percakapan telepon. Kategorisasi pengetahuan ini akan memunculkan pengetahuan baru. d. Explicit to tacit communication (Internalization) merupakan proses mengubah pengetahuan eksplisit menjadi tacit dan dekat dengan konsep pengalaman karena mengerjakan (learning by doing) misalnya sebuah laporan dan menyimpulkan gagasan baru atau mengambil tindakan konstruktif.

Proses perpindahan pengetahuan Nonaka dan Takeuchi tersebut mengedepankan proses berbagi pengetahuan (knowledge sharing). Allameh et.al (2012) di dalam sebuah organisasi berbagi pengetahuan kerap dapat terjadi karena ada kerelawanan di dalam sebuah organisasi. Knowledge Sharing menjadi salah satu metode mengukur KM, karena jumlah Knowledge Sharing baik eksplisit maupun tacit yang dipertukarkan dalam sebuah organisasi akan berpengaruh pada penerapan KM.

Capturing Knowledge atau penyerapan pengetahuan adalah sebuah proses yang merupakan hasil pemikiran seorang pakar sehingga pengalaman dapat ditangkap dengan baik. Dalam menghasilkan Manajemen pengetahuan, seorang pembuat/ pembangun aplikasi manajemen pengetahuan bekerjasama dengan pakar yang bersangkutan untuk menerjemahkan ke aplikasi yang sudah terprogram. Proses capture knowledge dapat dilakukan dengan beberapa hal, antara lain:

Proses capture knowledge dapat dilakukan dengan beberapa hal, antara lain :

\section{a. On-site Observation (Pengamatan ditempat)}

Yakni suatu proses interpretasi, dan merekamkelakuan suatu penyelesaian masalahdi suatu lokasi. Keuntungan dari On-site Observation adalah :

- Lebih banyak mendengar daripada berbicara.

- Tidak membutuhkan banyak biaya. Namun disamping itu, kelemahan dari proses on-site observation adalah :

- Beberapa pakar tidak senang jika diamati.

- Proses dapat saja menjadi kacau satu sama lain 


\section{b. Brainstorming (Bertukar Pikiran)}

Merupakan sebuah pendekatan terhadap suatu pemecahan untuk sebuah permasalahan, secara tidak terstruktur. Pada kehidupan sehari- hari, proses ini dapat digambarkan ketika kita bercerita terhadap orang lain, dan mendapatkan masukan dan saran dari orang tersebut.

c. Electronic Brainstorming

Merupakan pendekatan yang menggunakan komputer untuk bertukar pikiran dengan banyak pakar dalam satu waktu, kegiatan ini dapat dicontohkan dengan salah satunya kita melakukan suatu Confrence pada sebuah virtual office dengan lebih dari satu pakar dalam satu waktu. Biasanya proses ini diawali dengan suatu proses perencanaan untuk mengidentifikasi sasaran, tujuan dan struktur agenda dari proses ini. Kelebihan dari proses ini salah satunya adalah dengan banyaknya pakar yang terlibat, maka proses ini memungkinkan opini yang keluar tidak bertabrakan. Untuk para pakar yang pasif atau mungkin kurang percaya diri dalam beropini, proses ini dapat menyamarkan para pakar yang dimaksud diatas, sehingga mencegah adanya penilaian secara individu masingmasing pakar.

\section{d. Nominal Group Technique}

Yakni sebuah metode dalam pembuatan keputusan yang digunakan diantara beberapa kelompok yang ingin menghasilkan keputusan secepatnya, menggunakan voting, tetapi dengan ketentuan semua saran dan masukan dari berbagai group diakomodir.

NGT (Nominal Group Technique) dapat digunakan ketika:

- $\quad$ Salah satu anggota sebuah kelompok lebih vocal dibanding yang lainnya.

- Salah satu anggota suatu kelompok berfikir 'diam' lebih baik dari apapun.

- Adanya salah satu kecenderungan seorang anggota suatu kelompok tidak ikut berpartisipasi.

- Ada suatu kelompok tidak memberikan sejumlah gagasan

- $\quad$ Ada anggota group baru yang masuk ke tim.

- $\quad$ Terjadi Konflik

\section{e. Repertory Grid}

Seorang pakar dilihat sebagai seorang ilmuwan yang mengkategorikan suatu masalah menggunakan model dari expert itu sendiri. Dengan begitu ketika suatu kelompok melakukan diskusi, dengan lebih dari satu pakar, maka tiaptiap pakar mempunyai kemungkinan memodelkan suatu permasalahan secara berbeda atau tak sama. Grid digunakan untuk menangkap dan mengevaluasi pemodelan permasalahan yang dilakukan pakar. Kelebihan dan Kelemahan dalam proses repertory grid adalah:

- Menyarankan agar pakar berpikir lebih serius, tentang permasalahan dan bagaimana memecahkannya.

- Susah di kelola ketika suatu grid yang besar dengan ditambah detail yang kompleks.

- Karena memiliki sifat kompleks dan dapat di kelola, cara inibiasa digunakan, di awal-awal perolehan pengetahuan (knowledge capture)

\section{f. Delphi Method}

Merupakan salah satu metode survey seorang pakar untuk mendapatkan solusi dari sebuah permasalahan, biasanya pakar menggunakan quisioner yang diberikan untuk pakar lainnya untuk menyatukan tanggapan guna menyelesaikan suatu permasalahan yang sulit. Adapun kelebihan dan kekurangan dari metode ini adalah:

- Responden dapat dirahasiakan.

- Tanggapan dapat di kontrol.

- Data dapat ditampilkan secara statistik.

- Dengan begini pakar terlihat seperti kekurangan pengetahuan dalam penarikan keputusan final.

- Quisioner yang tidak di desain dengan baik dapat menimbulkan beberapa permasalahan. 


\section{g. Mapping Concept}

Merupakan sebuah kumpulan konsep yang mengandung cabang dan mata rantai. Cabang merepresentasikan suatu konsep dan mata rantai merepresentasikan hubungan antar konsep. Cara ini merupakan salah satu jalan yang efektif untuk suatu kelompok agar berfungsi tanpa kehilangan kepribadiannya masingmasing.

\section{Metodologi Penelitian}

Pada penelitian ini menggunakan metode penelitian deskriptif, dimana penelitian ini bertujuan untuk memberikan atau menjabarkan suatu keadaan atau fenomena yang terjadi saat ini dengan menggunakan prosedur ilmiah untuk menjawab masalah secara aktual (Sugiyono, 2011) karena dalam penelitian ini, penulis berusaha mendeskripsikan sebuah masalah atau fenomena yang terdapat pada Politeknik Perkapalan Negeri Surabaya. Data dikumpulkan dengan teknik penyebaran kuisioner yang terstruktur dengan metode pengambilan sampel menggunakan purposive sampling. Objek penelitian ini adalah penerapan knowledge sharing terhadap mahasiswa Manajemen Bisnis Maritim Politeknik Perkapalan Negeri Surabaya.

Beberapa pendekatan yang dilakukan adalah penyebaran kuisioner yang terstruktur yaitu penyebaran kuisioner yang dilaksanakan secara terencana dengan daftar pertanyaan yang telah dipersiapkan sebelumnya. Teknik sampling dalam penelitian ini menggunakan teknik purposive sampling, dengan populasi yakni mahasiswa Manajemen Bisnis Maritim PPNS. Responden dalam penelitian ini adalah mahasiswa Manajemen Bisnis Maritim khususnya angkatan 2015 dan 2016.

\section{Hasil dan Pembahasan}

Analisis Profil Responden Hasil analisis data profil responden yang diperoleh penulis yaitu 100 orang Mahasiswa Manajemen Bisnis Maritim di PPNS dengan responden laki-laki sebanyak 42 orang (42\%), responden perempuan sebanyak 58 orang (58\%). Observasi penyebaran kuisioner dilakukan tepat 2 minggu ketika mahasiswa sedang menjelang Ujian Akhir Semester dengan mengadakan kegiatan belajar bersama. Dalam proses tersebut, kami mengamati bagaimana penerapan knowledge sharing dari mahasiswa sendiri.

Dibawah ini merupakan hasil dari penyebaran kuisioner yang terstruktur dengan metode pengambilan sampel menggunakan purposive sampling di Politeknik Perkaplan Negeri Surabaya mengenai knowledge management dan melakukan kegiatan knowledge sharing yang kami ambil samplenya kepada mahasiswa Manajemen Bisnis Maritim khususnya angkatan 2015 dan 2016 dengan memberikan 6 pertanyaan dan diperoleh hasil sebagai berikut:

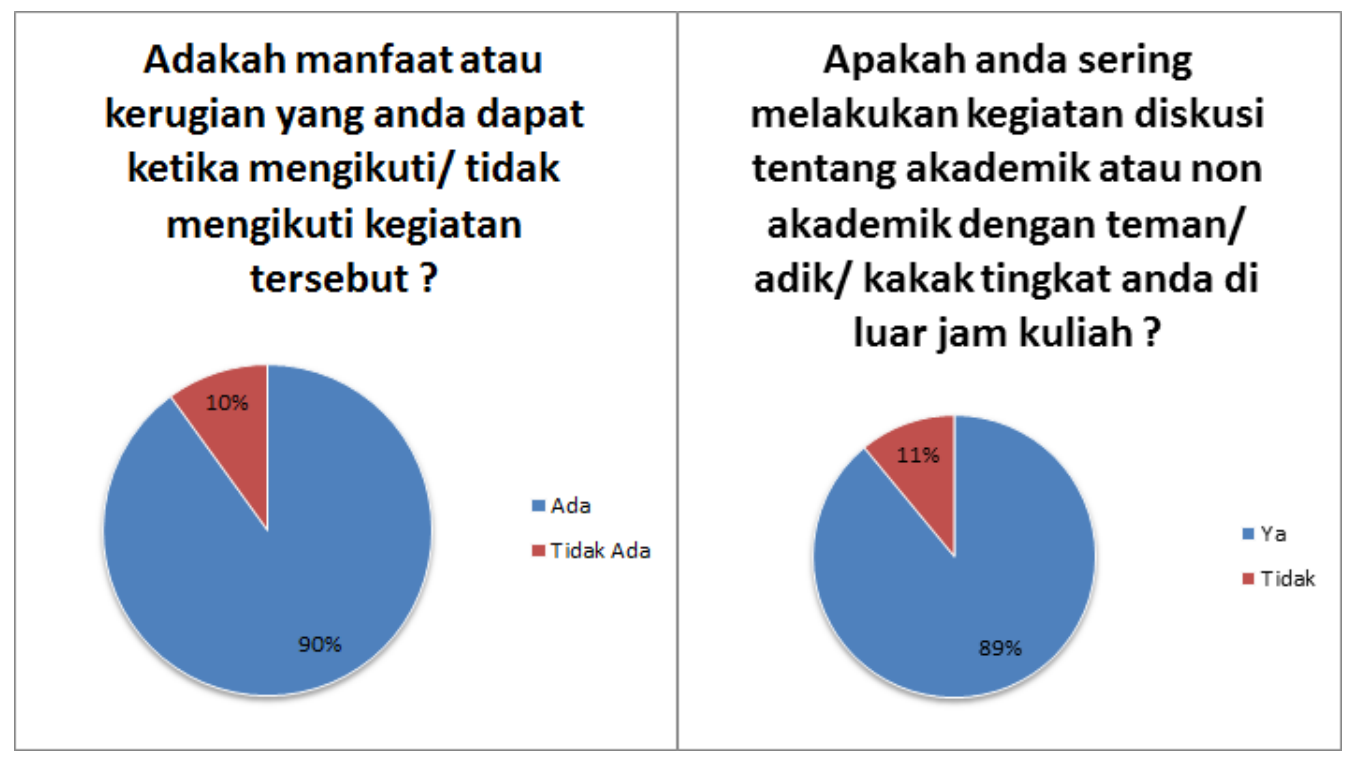



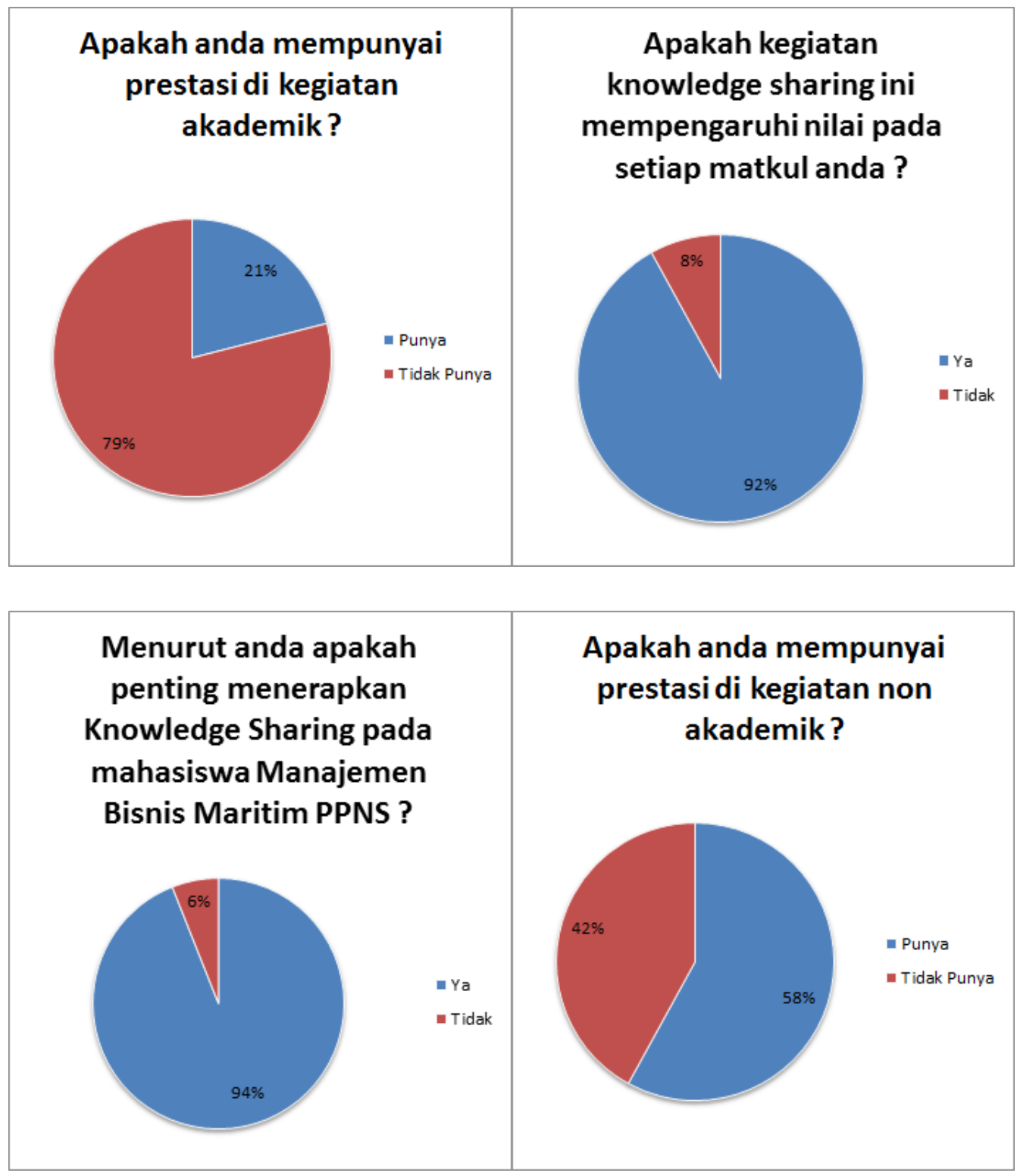

\begin{tabular}{|c|l|l|}
\hline No & \multicolumn{1}{|c|}{ Model SECI } & \multicolumn{1}{c|}{ Komponen KMS } \\
\hline 1 & Socialization & $\begin{array}{l}\text { Mahasiswa dapat saling berbagi pengetahuan yang telah mereka dapatkan selama } \\
\text { satu semester ini dalam bentuk belajar bersama }\end{array}$ \\
\hline 2 & Eksternalisasi & $\begin{array}{l}\text { Mendokumentasik an kegiatan diskusi/ belajar } \\
\text { bersama }\end{array}$ \\
\hline 3 & Combination & $\begin{array}{l}\text { Mengembangkan hasil dokumentasi kedalam beberapa model media } \\
\text { pencatatan/notulen }\end{array}$ \\
\hline 4 & Internalization & Mengembangkan hasil dokumentasi ilmu dengan menambahkan knowledge baru \\
\hline
\end{tabular}

Berdasarkan hasil dari pengambilan sampling bahwa masih banyak mahasiswa Manajemen Bisnis Maritim PPNS melakukan diskusi/ belajar bersama, namun masih tidak sejalan/ tidak berpengaruh secara signifikan terhadap prestasi, rata-rata mereka belum pernah menerapkan knowledge Sharing namun mayoritas mereka menganggap bahwa menerapkan berbagi pengetahuan kepada mahasiswa Manajemen Bisnis Maritim PPNS itu penting.

Berdasarkan hasil kedua analisis, dapat ditarik kesimpulan bahwa knowledge Sharing sangat perlu untuk mendorong dalam Prestasi Mahasiswa Manajemen Bisnis Maritim di PPNS dan harus segera dilakukan. Upaya 
utama yang harus dilakukan adalah dengan cara mengajak turut serta peran mahasiswa Manajemen Bisnis Maritim PPNS dalam hal penyebaran knowledge sharing lebih menyeluruh, dengan mengadakan diskusi/ kumpul bersama dan sebagainya untuk sadar akan pentingnya berbagi pengetahuan untuk mendorong dalam Prestasi Mahasiswa Manajemen Bisnis Maritim di PPNS.

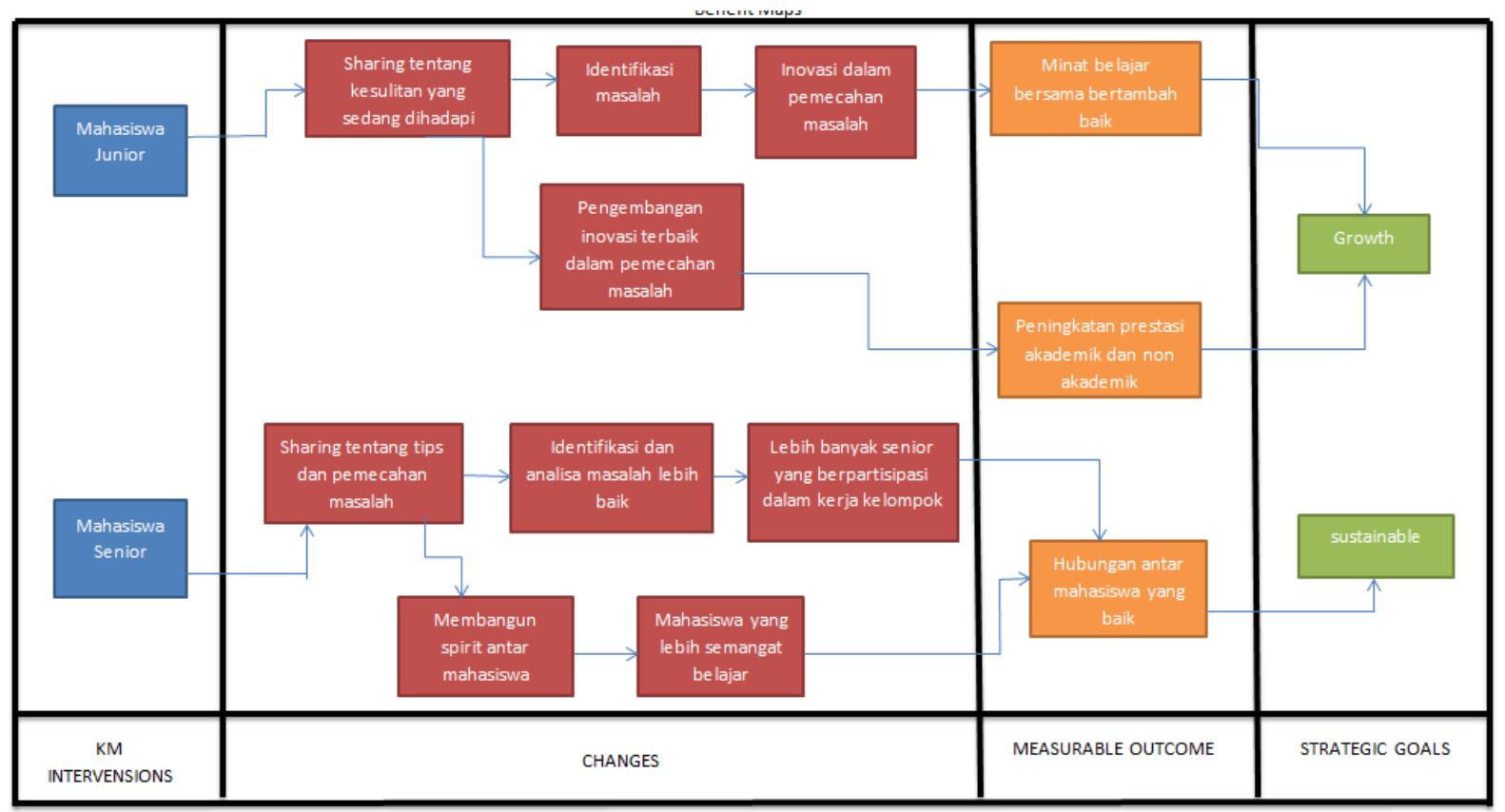

\section{Penutup}

Penerapan Knowledge Sharing di Manajemen Bisnis Maritim PPNS belum diterapkan secara maksimal karena masih tidak berpengaruh secara signifikan terhadap prestasi sehingga terkesan sulit untuk diterapkan. Namun hal tersebut bisa ditangani dengan memberikan perhatian khusus mengenai pentingnya menerapkan knowledge sharing sehingga dapat mendorong dalam
Prestasi Mahasiswa Manajemen Bisnis Maritim di PPNS.

Keterbatasan penelitian ini hanya menggunakan sampel relatif sedikit (100 responden) yang berasal dari Mahasiswa Manajemen Bisnis Maritim di PPNS, sehingga hasilnya belum optimal, dan penelitian kedepan dapat diarahkan pada jurusan lainnya dengan harapan diperoleh hasil yang lebih sempurna.

\section{Daftar Pustaka}

Giuma Omar Al Ahmar, Ainur Rofiq, Djumilah Hadiwidjojo. "The Impact of Knowledge Management, Learning Organization, and Educations Organization on Organization Performance: A Case in Brawijaya University". Asia-Pacific Management and Business Application 3 (1) 28 -47CUB 2014 University of Brawijaya Malang, Indonesia. 